\title{
Effect Of Legal Counsel Activity On The Cost Of Municipal Bond Offerings
}

Peyton Foster Roden (E-mail: www.coba.unt.edu./firel/roden), University of North Texas Stephen L. Poe ( E-mail: www.coba.unt.edu/firel/poe), University of North Texas Mike Braswell (E-mail: www.coba.unt.edu/firel/braswell), University of North Texas

\begin{abstract}
The authors examine the relationship between interest cost to the issuer of municipal bonds and legal counsel associated with the offering. Modeling interest cost with explanatory variables reflecting legal counsel, issue characteristics, and conditions in the financial markets, the authors conclude that offerings in which an active bond counsel participated had average interest costs statistically significantly lower than those without such counsel. Offerings involving issuer=s counsel and activity of underwriter $=$ s counsel experienced statistically higher average interest costs than otherwise. The authors note that their results are consistent with the certification hypothesis.
\end{abstract}

\subsection{Introduction}

P

ublicly available sources of information including bond rating agents, analysts, underwriters, and legal counsel exist to help issuers and investors evaluate an offering=s risk and price. J. M. Keynes might have been referring to any of these participants (he was in fact referring to underwriters) when he noted, AThey are very much concerned with their reputation and with the 'success' of their issues from the point of view of those who have purchased them.@ [1930, p. 368] Akerlof [1970] noted that development of institutional and contractual arrangements (like that between issuers and counsel) permits markets to function when information is biased either toward buyers or sellersCas when buyers cannot distinguish lemons from cream puffs.

Myers and Majluf (1984) showed that successful companies $C$ and by inference, municipalities Cmay forgo investment opportunities rather than issue new securities because the offerings of successful issuers will be pooled with those of unsuccessful issuers. This bias is overcome when issuers have a credible way to reveal information to investors. Issuers credibly reveal information through the use of third-party certification by players in the primary market, such as bond-rating agencies, underwriters, and legal counsel.

Although research regarding bond ratings and the information contained in choice of underwriter is rich and varied, it has generally ignored other players in the primary market. This paper contributes to previous studies by examining the relationship between legal counsel and cost to the issuer of municipal bonds. The municipal bond market is worthy of investigation because it differs from the market for equities and corporate bonds in several ways: Interest income from a municipal bond is exempt from federal taxation; the market for municipal offerings is regional rather than national; commercial banks often serve as underwriters of municipal offerings; and municipal bond offerings are subject to fewer disclosure requirements than are corporate bond and stock offerings.

Activity and the associated public exposure of legal counsel may improve market efficiency by determining the expected level of informed investor activity. The certification hypothesis suggests that some issuers would offer securities at too low a price without a knowledgeable and recognizable counsel to certify the quality of an offering. Booth and Smith [1986, p. 264] note that when insiders fail to communicate credibly their beliefs or when outsiders

Readers with comments or questions are encouraged to contact the authors via email. 
cannot buy useful information, a potential market failure is the result. This potential suggests that issuers are motivated to use knowledgeable legal counsel to certify the issue price and that outsiders use them as markers for quality.

Evidence of the impact of legal counsel in the bond market has been anecdotal. For example, a reporter for The Wall Street Journal [Peers (1988)] described an attempt in the municipal bond market to reduce expenses by ending the use of bond counsel. In early 1988 the Port Authority of New York and New Jersey tried to offer \$100 million without an independent legal opinion, using only the issuer $=\mathrm{s}$ counsel. By not getting an outside opinion from a bond counsel, PONYNJ saved \$25,000. [Peers (1988)] A Washington state legislative committee considered a proposal to use only issuer $=\mathrm{s}$ counselC the Attorney GeneralCon state offerings. Strong opposition from the Attorney General=s office helped to defeat the proposal, which would have saved the state about $\$ 200,000$ annually. [Peers (1988)]

Part 1 of the paper examines the literature on the role of bond counsel and of two other legal counsel often associated with a municipal bond offering, issuer $=\mathrm{s}$ and underwriter $=\mathrm{s}$ counsel. Part 2 describes the sample of 340 offerings examined in this study and includes a discussion of the statistical methodology used to build a model of interest cost. Part 3 discusses variables used to test hypotheses. Independent variables reflect the counsel, issue characteristics, and market influences.

Part 4 presents results of statistical analysis. Based on a regression model, the main findings are as follows: Interest cost is significantly associated with choice of legal counsel. Specifically, we find that when controlling for other influences, average interest cost to issuers (1) declines as bond counsel activity increases and (2) increases when underwriter $=\mathrm{s}$ counsel activity increases and when issuer $=\mathrm{s}$ counsel is present. Part 5 concludes the paper and offers useful explanations.

\subsection{Counsel Role}

In an imperfect financial market in which some participants have an informational advantage over others, legal counsel lease their knowledge and reputations to issuers. In this way, they assist issuers in pricing their offerings and investors in sorting out lemons from cream puffs. Three sets of counsel are associated with a bond offering: bond counsel, issuer $=\mathrm{s}$ counsel, and underwriter $=\mathrm{s}$ counsel. The following discussion briefly explains the role of each in a municipalbond offering.

Use of bond counsel in municipal financing transactions originated from the need to provide assurance to prospective bondholders. That remains true today. As Ettlinger and Koehane [1993, p. 702] assert, AA more complex financial market and an ever-changing tax regulatory scheme justify a bewildered investor's increased reliance upon the expertise of bond counsel both to determine the structure of a municipal financing and to effect legal compliance with such structure.@

Municipal bond offerings are subject to fewer disclosure requirements than are corporate bond and stock offerings. [Hume (1995)] Given the comparative lack of required disclosure and information about the financial status of the political agency issuing the bonds, we argue that investors may be more likely to rely on the legal opinion issued by bond counsel as to the soundness of the bond issue. It is reasonable to assert that the more reliance investors place on the legal opinion, the more impact the choice of bond counsel should have on the interest cost of the offering.

Issuer $=\mathrm{s}$ counsel may be called on to assist with a variety of matters. For example, issuer $=\mathrm{s}$ counsel helps to draft necessary documentation and to secure required regulatory approvals. It also helps to complete procedural steps for the issue and to provide information to bond counsel and underwriter $=\mathrm{s}$ counsel for use in drafting bond documents. [Petersen (1993), pp 642B644] Unlike bond counsel, however, the focus of issuer=s counsel is to represent the interests of the issuer, and in each of these matters issuer $=\mathrm{s}$ counsel may negotiate with bond counsel on behalf of the issuer.

Underwriter $=\mathrm{s}$ counsel plays a role in developing the financial scheme employed by the underwriter to finance purchase of the bonds (when appropriate) and in assisting bond counsel with drafting and reviewing bond documentation. [Smith and Pirog (1983), pp. 239B243] At closing, underwriter=s counsel issues an opinion that the 
disclosure obligations of the underwriter have been satisfied under federal and state securities laws.

The adversarial role of the underwriter $=\mathrm{s}$ counsel ensures that the contract between issuer and underwriter adequately protects the underwriter $=\mathrm{s}$ interests and that the underwriter performs its obligation to make adequate disclosure when marketing the bonds to the public. The adversarial nature of the underwriter $=\mathrm{s}$ counsel is underscored by litigation such as a 1994 case in which a jury ordered a Detroit law firm to pay more than $\$ 22$ million to a municipal-bond issuer for failing to disclose that the firm represented both underwriter and issuer. [Stevens (1994)]

\subsection{Data And Methodology}

\subsection{Data}

The data set (acquired from Securities Data Company) consisted of 340 municipal bond offerings by Texas issuers during 1995. Exhibit 1 shows descriptive statistics of summary variables. Average activity by the issuers consisted of three offerings; however, the maximum number of offerings was eight. Average maturity of the 253 offerings with such information was 9.73 years with a standard deviation of 3.33 years. Offering size varied dramatically. The smallest offering was $\$ 50,000$ and the largest, $\$ 300$ million. The standard deviation was $\$ 39.06$ million.

EXHIBIT 1: Summary Statistics of Municipal Offerings in the Data Set ${ }^{a}$

\begin{tabular}{|l|l|l|l|l|l|}
\hline & \multicolumn{1}{|c|}{ Maximum } & \multicolumn{1}{c|}{ Mean } & \multicolumn{1}{c|}{ Minimum } & Std Deviation & \multicolumn{1}{c|}{ Valid N } \\
\hline Issuer activity $^{\mathrm{b}}$ & 8 & 3 & 1 & 3 & 340 \\
\hline Maturity $^{\mathrm{c}}$ & 35 & 9.73 & 1.29 & 3.33 & 253 \\
\hline Amount of offering $\mathrm{d}$ & $\$ 300.00$ & $\$ 18.42$ & $\$ .05$ & $\$ 39.06$ & 340 \\
\hline True interest cost & $9.32 \%$ & $5.94 \%$ & $4.17 \%$ & $.86 \%$ & 70 \\
\hline Net interest cost & $9.37 \%$ & 5.79 & $3.61 \%$ & $.63 \%$ & 156 \\
\hline Long-term rate $^{\mathrm{e}}$ & $8.09 \%$ & $7.33 \%$ & $6.58 \%$ & $.47 \%$ & 340 \\
\hline Short-term rate $^{f}$ & $6.21 \%$ & $5.95 \%$ & $5.64 \%$ & $.13 \%$ & 340 \\
\hline
\end{tabular}

a 340 Texas municipal offerings, January 1, 1995BJune 30, 1995.

b Number of times issuer is in data set.

c Years and fraction of a year.

d Millions of current dollars.

e Effective yield on a 30-year treasury bond.

f Effective yield on a 13-week T-bill.

Interest costs in the data set were measured in two different ways, net interest cost and true interest cost. Each measure yielded similar descriptive statistics. True interest cost calculated as an annual rate compounded annually ranged from $4.17 \%$ to $9.32 \%$ with a standard deviation of $0.86 \%$. Equivalent values for net interest cost were $5.79 \%$ and $9.37 \%$ with a standard deviation of $0.63 \%$.

Two variables in Exhibit 1 describe the interest rate environment during the period examined in the paper. Long-term rates (measured by the effective yield on 30-year maturity Treasurys) ranged from $7.33 \%$ to $6.58 \%$ with a standard deviation of $0.47 \%$. Short-term rates (measured by the effective yield on 13 -week maturity Treasurys) had a range of 57 basis points, from $5.64 \%$ to $6.21 \%$ with a standard deviation of $0.13 \%$.

\subsection{Methodology}

Our statistical method of choice was categorical regression with optimal scaling (Meulman, 2001), which extends the standard approaches of regression and loglinear modeling by quantifying categorical variables. ${ }^{1}$ Terza 
(1987) notes that employing ordinal qualitative regressors may produce substantial efficiency gains and bias reduction in the estimation of qualitative shifts in the regression line relative to the use of the conventional dummy-variable approach.

We assigned simultaneously scale values to independent variables reflecting nominal, ordinal, and numerical variables to reflect characteristics of the original categories. ${ }^{2}$ The methodology maximizes the squared correlation between the transformed response and the weighted combination of transformed predictors.

\subsection{Variables In The Analysis}

Model building began by selecting variables used in previous studies to measure the influences on interest cost to the issuer. The dependent variable was interest cost, and independent variables reflected legal counsel, issuer characteristics, and market conditions.

\subsection{Dependent Variable}

True interest cost (TIC) was our choice on theoretical grounds to use as the dependent variable because it recognizes opportunity cost. [Fortune (1991); Mumy (1978); Sorensen (1980)] True interest cost is the expected rate of return on investment to the investor calculated iteratively as a single discount rate equating the present value of the debt-service payments to the issue price net of issue costs.

Net interest cost (NIC) is an alternative to true interest cost (or present value interest cost) as a measure of the cost to an issuer. [Hopewell and Kaufman (1974); Osteryoung, Braswell, and Blevins (1979)] Net interest cost is the undiscounted sum of interest payments an issuer makes over the maturity of the issue less any premium measured by the projected offering price less underwriter spread and face value of the issue, all divided by the number of bond years in the issue, that is, the sum of the number of bonds of each serial maturity multiplied by that maturity in years. Bierwag [1981] and West [1968 ] have noted the differences between TIC and NIC, demonstrating the excess costs to the issuer and determining beneficiaries when NIC is used as an acceptance criterion.

We completed statistical analyses using NIC as the dependent variable (156 issues) and, separately, TIC (70 issues). Results were similar with each. We were concerned about the sample sizes and loss of information from excluding observations with missing values, so we considered combining them. Bierwag [1981, pp. 104B107] noted that theoretically and practically NIC and TIC typically lead to the same rank order: AFor the most part then, even after accounting for differences in spreads and prospective yields, the lowest NIC bid also implies the lowest TIC bid. @ [1981, p. 105]

We used Bierwag=s suggestion to examine in our sample the relationship between NIC and TIC. There existed a very good linear fit between true interest cost and net interest cost for the common portion of the sample offerings. Noting the correlation $(\rho=0.935)$ and then the linearity in a scatterplot of TIC and NIC ordered in time, we then used regression analysis to determine coefficients in estimating interest cost for those offerings lacking TIC $(\alpha=0.52$, $\left.\beta_{1}=0.93, \mathrm{R}^{2}=0.874\right)$. Consequently, the reported results combine the two samples. The procedure increased the number of useable offerings from 156 (with net interest cost reported) and 70 (with TIC reported) to 187.

For computational purposes (the CATREG program truncates fractional values after a decimal), we converted the dependent variable to basis points. To minimize output we used consecutive integers beginning with 1 by subtracting from each observation the minimum and adding one to the result.

\subsection{Counsel Characteristics}

Measuring prestige of an investment banker is well established in the literature: One need only to look at the relative position in published tombstones. Alas, no established method exists to measure prestige of legal counsel. Law firms serving as legal counsel typically are recognized anecdotally as those ?... with an established reputation in the 
investment community for experience, expertise, and reliability in municipal finance.@ [Kraft (1983), p. 228] We realized that developing a measure of legal counsel prestige would be problematic.

We turned for a measure of prestige to The Bond Buyer, a national trade publication which publishes annual rankings of the nation=s top bond counsel. These rankings show 35 firms based on the dollar amount of municipal bond offerings handled by each. The Bond Buyer offers no independent ranking of quality or reputation. However, inclusion in these national rankings implies that a firm is among the nation=s leading law firms in terms of the dollar amount of bond transactions handled. Moreover, an increased volume of offerings means that the legal counsel=s work is exposed often to the scrutiny of the market place.

To argue that the volume of underwritings is a reliable measure of high prestige may be incorrect. One could counter that high volume suggests a willingness of the legal counsel to do any issue without much regard to quality of the certification rendered. Consequently, we take the conservative approach of examining the activity of the counsel and its relationship to interest cost and hesitate to make inferences regarding reputation.

\subsection{Bond Counsel}

The data set included six bond counsel from The Bond Buyer rankings of 35 legal counsel. Their rankings (in rank order from highest to lowest) and the number and average size of offerings (in millions) in the data set were as follows : Chapman Cutler (4 offerings, \$13.72); McCall (90, \$23.01); Fulbright (100, \$18.67); PeckBShaffer (2, \$0.58); Vinson (62, \$20.97); and Hutchison (6, \$2.33).

Exhibit 2 shows summary statistics associated with presence of an active bond counsel for a particular offering. Offerings with bond counsel included in this ranking had lower average net and true interest costs (5.8\% and $5.8 \%$ ) than those without such counsel (5.9\% and 6.3\%). Average activity of issuers with active bond counsel and that of their less active counterparts were similar. Average maturity of offerings with active bond counsel was slightly less than their non-prestigious counterparts (9.66 years and 10 years, respectively), but the larger standard deviation of the active offerings suggests greater variability among offerings.

EXHIBIT 2. Active Bond Counsel and Summary Values ${ }^{\text {a }}$

\begin{tabular}{|l|l|l|l|l|l|l|l|l|}
\hline & \multicolumn{4}{|c|}{ Not Active (unranked) } & \multicolumn{4}{c|}{ Active (ranked) } \\
\cline { 2 - 9 } & Mean & Maximum & Minimum & Std Deviation & Mean & Maximum & Minimum & $\begin{array}{c}\text { Std } \\
\text { Deviation }\end{array}$ \\
\hline NIC & $5.9 \%$ & $9.4 \%$ & $4.9 \%$ & $0.8 \%$ & $5.8 \%$ & $7.6 \%$ & $3.6 \%$ & $0.6 \%$ \\
\hline TIC & $6.3 \%$ & $9.3 \%$ & $5.0 \%$ & $1.1 \%$ & $5.8 \%$ & $8.2 \%$ & $4.2 \%$ & $0.7 \%$ \\
\hline Activity & 2 & 8 & 1 & 1 & 2 & 8 & 1 & 1 \\
\hline Maturity & 10 & 32 & 2.88 & 3.71 & 9.66 & 35 & 1.29 & 3.23 \\
\hline $\begin{array}{l}\text { Offering } \\
\text { size }\end{array}$ & $\$ 12.1$ & $\$ 300$ & $\$ 0.2$ & $\$ 36.9$ & $\$ 20.3$ & $\$ 300$ & $\$ 0.1$ & $\$ 39.5$ \\
\hline
\end{tabular}

a Prestige determined by appearance in The Bond Buyer.

$b$ Years and fraction of a year.

c Millions of current dollars.

Exhibit 3 presents information regarding categorical values and the presence of an active bond counsel in an offering. Though generally similar between the two broad classifications, two values are noteworthy. Offerings without active bond counsel were typically negotiated $(52 \%)$ and consisted of low-rated bondsCBB and BBB. In all other categories, active bond counsel prevailed proportionally. 
EXHIBIT 3. Bond Counsel Activity and Categorical Variables

\begin{tabular}{|c|c|c|c|c|c|c|}
\hline & & \multicolumn{2}{|c|}{ Not Active } & \multicolumn{2}{|c|}{ Active } & \multirow[b]{2}{*}{$\begin{array}{c}\text { Row } \\
\text { Number }\end{array}$} \\
\hline & & Number & Row $\%$ & Number & Row \% & \\
\hline \multirow[b]{2}{*}{ Offering type } & Competitive bid & 65 & $35.9 \%$ & 116 & $64.1 \%$ & 181 \\
\hline & Negotiated & 77 & $52.4 \%$ & 70 & $47.6 \%$ & 147 \\
\hline \multirow[b]{2}{*}{ Bond type } & GO & 97 & $44.3 \%$ & 122 & $55.7 \%$ & 219 \\
\hline & Revenue & 45 & $38.8 \%$ & 71 & $61.2 \%$ & 116 \\
\hline \multirow[b]{2}{*}{ Credit enhancement } & None & 94 & $45.6 \%$ & 112 & $54.4 \%$ & 206 \\
\hline & Enhanced & 52 & $38.8 \%$ & 82 & $61.2 \%$ & 134 \\
\hline \multirow[b]{2}{*}{ Call } & Not callable & 43 & $41.2 \%$ & 64 & $59.8 \%$ & 107 \\
\hline & Callable & 103 & $44.2 \%$ & 130 & $55.8 \%$ & 233 \\
\hline \multirow[b]{6}{*}{ Rating } & Not rated & 38 & $45.2 \%$ & 46 & $54.8 \%$ & 84 \\
\hline & $\mathrm{BB}$ & 1 & $100.0 \%$ & 0 & 0 & 1 \\
\hline & BBB & 6 & $66.7 \%$ & 3 & $33.3 \%$ & 9 \\
\hline & $\mathrm{A}$ & 4 & $44.4 \%$ & 5 & $55.6 \%$ & 9 \\
\hline & AA & 10 & $38.5 \%$ & 16 & $61.5 \%$ & 26 \\
\hline & AAA & 77 & $40.5 \%$ & 113 & $59.5 \%$ & 190 \\
\hline
\end{tabular}

We coded this variable (scaled ordinally) 1 if the counsel were not included in The Bond Buyer and 2 through 6 to reflect the relative rankings, where 6 was the top-ranked bond counsel, Chapman Cutler. In terms of statistical testing, the question is whether $\beta_{1} \square 0$. We expect this coefficient to be negative to reflect favorably the certification by an active and knowledgeable bond counsel.

\subsection{Issuer=s Counsel}

None of the issuer=s counsel in our data set was in The Bond Buyer listing. However, we wanted to include a categorical variable to capture the influence.

Panel A in Exhibit 4 shows summary values of each offering classified according to whether or not the issuer used a counsel. The exhibit shows that offerings with issuer $=\mathrm{s}$ counsel had higher average NICs and TICs than those without counsel. Maturity of the offerings with issuer $=\mathrm{s}$ counsel was on average slightly less than one year greater than that of the offerings in which issuers did not use a counsel, and both groups were roughly equally active. Average size of an offering was $\$ 20.5$ million for those with an issuer=s counsel, $\$ 18.3$ for those without.

Issuer $=\mathrm{s}$ counsel was scaled nominally and coded 1 if not present and 2 otherwise. In terms of statistical testing, the question is whether $\beta_{2} \square 0$. We expect this coefficient to be negative because of the adversarial nature of the counsel.

\subsection{Underwriter $=\mathrm{s}$ Counsel}

The sample included nine underwriter=s counsel included in the rankings of The Bond Buyer. Their relative positions (from highest to lowest) in the rankings, and the number and average size of offerings in millions in the data set were as follows: Chapman Cutler (3 offerings, \$18.55); Squire BSanders $(2, \$ 58.2)$; Kutak $(3, \$ 5.14)$; McCall (10, \$9); Fulbright (15, \$15.68); GilmoreBBell (1, \$6.25); Vinson (10, \$39.24); Ballard (2, \$28.37); and DickinsonBWright $(1, \$ 5)$. 


\section{EXHIBIT 4. Summary Values, Issuer=s Counsel, and Underwriter=s Counsel Used in the Analysis}

Panel A. Presence of Issuer $=$ s Counsel and Summary Values ${ }^{\mathrm{a}}$

\begin{tabular}{|l|c|c|c|c|c|c|c|c|}
\hline & \multicolumn{4}{|c|}{ No Issuer=s Counsel } & \multicolumn{3}{c|}{ Issuer=s Counsel Present } \\
\cline { 2 - 9 } & Mean & Maximum & Minimum & $\begin{array}{c}\text { Standard } \\
\text { Deviation }\end{array}$ & Mean & Maximum & Minimum & $\begin{array}{c}\text { Standard } \\
\text { Deviation }\end{array}$ \\
\hline NIC & $5.74 \%$ & $7.65 \%$ & $3.61 \%$ & $0.55 \%$ & $7.18 \%$ & $9.37 \%$ & $6.46 \%$ & $1.23 \%$ \\
\hline True interest cost & $5.82 \%$ & $7.53 \%$ & $4.17 \%$ & $0.71 \%$ & $7.50 \%$ & $9.32 \%$ & $6.65 \%$ & $1.22 \%$ \\
\hline Activity & 2 & 8 & 1 & 1 & 2 & 5 & 1 & 1 \\
\hline Maturity (years) & 9.67 & 35 & 1.29 & 3.11 & 10.44 & 32 & 5.1 & 5.33 \\
\hline Offering Size & $\$ 18.27$ & $\$ 300$ & $\$ 0.05$ & $\$ 39.84$ & $\$ 20.51$ & $\$ 100$ & $\$ 0.25$ & $\$ 26.41$ \\
\hline
\end{tabular}

a Twenty-three offerings had issuer counsel.

Panel B. Activity of Underwriter $=\mathrm{s}$ Counsel and Summary Values ${ }^{\mathrm{a}}$

\begin{tabular}{|c|c|c|c|c|c|c|c|c|}
\hline & \multicolumn{4}{|c|}{ Active } & \multicolumn{4}{|c|}{ Active } \\
\hline & Mean & Maximum & Minimum & $\begin{array}{c}\text { Std } \\
\text { Deviation }\end{array}$ & Mean & Maximum & Minimum & $\begin{array}{c}\text { Std } \\
\text { Deviation }\end{array}$ \\
\hline NIC & $5.75 \% 2$ & $9.37 \%$ & $3.61 \%$ & $0.63 \%$ & $6.08 \%$ & $6.99 \%$ & $5.13 \%$ & $0.73 \%$ \\
\hline $\begin{array}{l}\text { True interest } \\
\text { cost }\end{array}$ & $5.88 \%$ & $9.32 \%$ & $4.17 \%$ & $0.88 \%$ & $6.29 \%$ & $6.85 \%$ & $5.21 \%$ & $0.59 \%$ \\
\hline Issuer activity & 2 & 8 & 1 & 2 & 2 & 5 & 1 & 1 \\
\hline $\begin{array}{l}\text { Maturity } \\
\text { (years) }\end{array}$ & 9.63 & 32 & 1.29 & 3.07 & 10.67 & 35 & 7.5 & 5.12 \\
\hline Offering Size & $\$ 18.1$ & $\$ 300$ & $\$ 0.05$ & $\$ 40.3$ & $\$ 20.7$ & $\$ 168.5$ & $\$ 0.2$ & 30.5 \\
\hline
\end{tabular}

a Activity determined by rank in The Bond Buyer. Thirty-three had active underwriter's counsel measured as discussed in the text.

Panel B of Exhibit 4 shows summary variables classified according to whether or not underwriter=s counsel was in The Bond Buyer rankings. Offerings in the data set with active underwriter=s counsel had higher average NICs and TICs than those without active underwriter $=\mathrm{s}$ counsel. However, standard deviations of the active set were smaller than those of their less active counterparts. Average maturity of the active offerings was only slightly longer than their less active counterparts (10.7 years versus 9.6 years), but the offerings with active underwriter=s counsel had a substantially larger standard deviation. Issuer activity and average offering size were generally similar between the two groups, although standard deviations varied substantially.

Activity of underwriter=s counsel $\left(\beta_{3}\right)$ was scaled ordinally and coded similarly to that of bond counsel: 1 if the counsel were not included in The Bond Buyer rankings and 2 through 9 to reflect the relative rankings, where 9 was the top-ranked underwriter=s counsel (Chapman Cutler). In terms of statistical testing, the question is whether $\beta_{3} \square 0$. We expect this coefficient to be positive to reflect the assistance of the counsel to the underwriter.

\subsection{Issue Characteristics}

Issue characteristics pertain to a specific offering. In this way, they are features over which the issuer itself has some control. Issue characteristics used in this study consist of those suggested in the literature: underwriter prestige, type of offering, negotiated or competitive bid, size of offering, rating, credit enhancement, call provisions, issuer activity, and average maturity of the offering.

\subsection{Underwriter Prestige}

We included a metric of underwriter prestige because other studies used it when examining the influence on offering prices and interest cost. [Carter and Manaster (1990); Johnson and Miller (1988); Roden and Bassler (1996)] 
Prestige of the managing underwriter and of members of the bulge bracket affects the pricing of a new issue.

We rely on the system of Hayes [1971] of Robertson [1973] in noting the rigid hierarchy of the investmentbanking industry discernible in tombstone announcements. Tombstones first list manager and co-manager firms, followed by the bulge bracket, the major bracket, and the sub-major bracket. Prestigious firms have upper-bracket positions. Less prestigious firms have positions in lower brackets. Tombstones list firms usually (but not always) alphabetically within brackets.

To develop the metric, we examined tombstones of municipal-bond offerings in the national edition of The Wall Street Journal for the three years 1993B1995. We noted the managing group, the bulge bracket, the major bracket, or otherwise. We combined managing and bulge brackets, leaving three categories. Underwriters in these three categories were compared with the list of lead underwriters in our data set and assigned the following (scaled ordinally): $3=$ major, $2=$ bulge, and $1=$ all others.

\subsection{Other Issue Characteristics}

Joehnk and Kidwell [1979] found statistical evidence that revenue bonds have a cost structure that differs from that of general obligation bonds, leading to higher interest cost to an issuer of revenue bonds. Thus, studies of costs and returns in the municipal bond market should include a variable to capture a higher interest cost to revenue bonds. To capture this influence, we classified values into two categories scaled ordinally: $1=$ general obligation and $2=$ otherwise (revenue).

Research [Joehnk and Kidwell (1979); Kidwell and Rogowski (1983)] suggests that negotiated issues have significantly higher interest costs than competitively bid issues have. This study uses four classifications of offerings to reflect the richness of types available in the data set. Rather than the typical classification of negotiated and competitively bid, the data set included negotiated public offerings, negotiated limited offerings (open to a limited number of underwriters), competitive bid, and private placements. These variables were scaled nominally and categorized as follows: $1=$ negotiated public, $2=$ negotiated limited, $3=$ competitive bid, and $4=$ private placement.

Issue size has been found to influence interest cost [Braswell (1981); Joehnk and Kidwell (1979); Kidwell and Rogowski (1983)] as a result of increasing returns. The sign of the issue-size coefficient depends on whether economies or diseconomies of scale exist. The following analysis includes the size of issue in current dollars to control for this effect. We scaled this variable as numeric, but did not recode it. However, we did adjust values to minimize output and to use consecutive integers beginning with one. That required us to subtract the minimum issue size $(\$ 5,000)$ from each value and to add one to the results.

Previous studies have found that bond ratings relate to interest costs of corporate and municipal debt. [Clarke (1997); Fortune (1991)] The usual method of handling such a variable is with zero-one dichotomous variables for each classification (minus one to establish a reference group). Categorical regression uses one variable scaled to reflect the number of classifications, thus simplifying interpretation.

The data set included ratings from both Standard \& Poor's Corporation and from Moody=s Investor Services. Offerings with split ratings have been found to trade at yields equal to those of the higher rating. [Hsueh and Kidwell (1988)] Therefore, offerings in the data set with split ratings were treated as though they had the higher rating. Ratings ranged from AAA through $\mathrm{BB}$ to not rated. For computational purposes, we scaled this variable ordinally and coded the ratings from 1 through 6 , with $\mathrm{AAA}=6$.

Credit enhancement may influence the rating. Insured bonds typically receive an AAA rating. However, bonds receiving an AAA rating because of the rating process may have interest costs lower than bonds that receive such a rating because of credit enhancement. [Hsueh and Kidwell (1988)] To control for such an influence, this study included a category scaled nominally of $1=$ not credit enhanced and $2=$ credit enhanced. 
Smith [1987] found the presence of a call provision to be a significant explanatory variable in his probit analysis of municipal offerings. A call provision offers an issuer the option of calling the bond and replacing it with another. Investors typically require a higher return to compensate them for the likelihood that the issuer will call the bond in a lower interest-rate environment, thus reducing investor wealth. This categorical variable, scaled nominally, was coded as $1=$ callable and $2=$ non-callable .

Previous research [Carter (1992); Roden and Bland (1986)] noted that issuer activity influences the interest cost of offerings. One interpretation of increased issuer activity is that it should contribute to lower interest cost because active issuers have experience in the primary market and thus may obtain lower interest costs. Moreover, their need to enter often the primary market exposes the issuer to increased scrutiny of the market place. Increased scrutiny reduces uncertainty surrounding the issuer $=\mathrm{s}$ ability to pay and so reduces the default risk premium included in interest cost. An alternative interpretation is that the need to enter often the primary market suggests that the issuer is poorly planning its cash flow requirements; thus, investors may perceive ineffective financial management and thereby increase the default risk premium applied to the offering. A measure of activity scaled numerically captured this influence. The variable was simply the number of times an issuer $=\mathrm{s}$ offerings appeared in the data set, where $1=$ minimum and $8=$ maximum.

Investors in bonds with long terms to maturity expose $c e t$. par. their portfolios to greater interest-rate risk than do investors in short-term securities. In addition, liquidity and transaction costs influence interest cost. Because of the serial nature of the municipal bond issue, maturity may affect the interest cost to the issuer. [Fortune (1991)] Longer maturity means more strips and smaller average size of strip, so this influence was recognized with a variable scaled numerically reflecting the period to first call (for callable bonds) or average maturity (for non-callable bonds). For computational purposes, we adjusted values to minimize output and to use consecutive integers beginning with one.

\subsection{Market Characteristics}

Financial theory suggests that risk of a municipal bond should be explained by the covariance of the security's return with the return on investment in a diversified portfolio. However, absence of a secondary market for issues in the sample restricted our choice of a risk measure. Ritter [1984] suggests a proxy for the theoretically-sound measure. He argues that issues with high variance are likely those for which a high degree of uncertainty exists at the time of the offering. To capture this influence, we developed a model of uncertainty in the bond market. Model building began by examining a scatterplot of the effective rate on the 30-year Treasurys in the data set ordered sequentially by time. Noting the observed trend in the rate, we then used exponential smoothing to model the expected rate. The resulting specification of uncertainty was similar to that of Ritter: The error at each observation calculated as the difference between the expected rate (fitted values from exponential smoothing) and the observed rate.

For computational purposes, we recoded values to minimize output and to use consecutive integers beginning with one. We scaled this variable as numeric.

The period examined in this paper was characterized by bond-market turmoil associated with the financial difficulties of Orange County, California. On December 6, 1994, Orange County=s investment fund (along with other investors in its investment portfolio) filed for bankruptcy protection. The county contended that every participant in the fund should bear its share of the $\$ 2.1$ billion in losses. On May 17, 1995, Orange County announced that default on its outstanding bonds was imminent. To capture the contamination of the municipal bond market from this announcement, we included a categorical value, 1 before May 17 and 2 otherwise. We scaled this variable as nominal.

\subsection{Results}

To begin analysis, we deleted offerings with missing values of the dependent variable. That left us with 187 offerings. We then verified that the minimum value for each variable was one and recoded as necessary. The remaining data set contained offerings with missing values for maturity, type of offering, and rating so further paring of the sample was required. Listwise deletion resulted in 153 cases for analysis as follows: 
Total offerings

Less offerings missing true interest cost or net interest cost Offerings with TIC or NIC

Less offerings with missing values

Maturity

Type of bond ( $\mathrm{GO}$ or revenue)

Rating

Total

Offerings used with listwise deletion

Missing data are a problem for any analysis. So it is appropriate to try different ways of dealing with the problem, then compare results and draw conclusions from the comparisons. Analysis was undertaken using two different methods for handling data missing randomly. (1) To listwise delete offerings missing any variable specified for analysis. (2) To substitute modes of valid values for each missing value when the correlation matrix is calculated. The authors note their preference for mode substitution because it does not discard usable offerings compared with listwise deletion. Moreover, it is non-biasing and essentially conservative because it weakens relationships among transformed values. The following discussion reports results using mode substitution. Results using listwise deletion (and other specifications of the dependent variable) are available from the authors.

Model building led to a regression equation with both analytic validity and predictive value. The top part of Exhibit 5 shows model summaries and analysis of variance. In general, the overall relationship between interest cost and many of the independent variables is statistically acceptable. Adjusted $\mathrm{R}^{2}$ and standard error of the estimate were respectively 0.592 and 0.410 , respectable for data of this kind. The model was statistically significant at the 0.01 level $(\mathrm{F}=20.29)$.

Exhibit 5 presents coefficients resulting from model building. An independent predictive relationship existed in the analysis for each of the three variables capturing legal-counsel roles. The sign on each coefficient reflects the partial correlation between changes in the average level of interest cost and each of the transformed variables. Pratt $=\mathrm{s}$ measure of relative importance shows that the set of bond counsel, issuer $=\mathrm{s}$ counsel, and underwriter $=\mathrm{s}$ counsel have an importance of $0.343(0.031+0.282+0.030)$, suggesting that legal counsel explain $34.3 \%$ of the variability in interest cost during the period examined.

Categories of bond counsel activity were associated with a lower average interest cost $\left(\beta_{1}=\mathrm{B} 0.098\right)$ and were statistically significant at the 0.05 level $(\mathrm{F}=3.912)$. In contrast to this negative influence, presence of issuer $=\mathrm{s}$ counsel $\left(\beta_{2}=0.043, \mathrm{~F}=68.027\right)$ and categories of underwriter $=\mathrm{s}$ counsel activity $\left(\beta_{3}=0.154, \mathrm{~F}=8.136\right)$ contributed to a statistically significant increase in the average level of interest cost in this data set. The sign on the coefficient for issuer $=\mathrm{s}$ counsel was opposite to that hypothesized, suggesting that this counsel $=\mathrm{s}$ presence sent a negative signal to the market.

Square of the partial coefficient in Exhibit 5 corresponds to the proportion of the variance explained relative to the residual response remaining after removing the effects of the other variables in the model. For example, the categories of bond counsel had a partial correl ation of B0.149. After removing the effects of other variables in the model, presence of an active bond counsel explained $2.22 \%\left(\mathrm{~B} 0.149^{2}\right)$ of the variation in interest cost. Similar values for issuer $=\mathrm{s}$ and underwriter $=\mathrm{s}$ counsel in Exhibit 5 are $28.3 \%\left(0.532^{2}\right)$ and $4.54 \%\left(0.213^{2}\right)$, respectively.

The authors tested the robustness of the signs and significance. We rescaled bond and underwriter $=\mathrm{s}$ counsel nominally (rather than ordinally as in Exhibit 5) and repeated the analysis. Signs and levels of significance remained essentially unchanged. We prefer the ordinal scale and its interpretation because it preserves the rank-order from The Bond Buyer. 


\section{EXHIBIT 5 Coefficients from Regression Analysis ( $N=187)$}

0.623

Adjusted $\mathrm{R}^{2}=0.592$
$\mathrm{F}=20.29 *$

$\mathrm{SEE}=0.410$

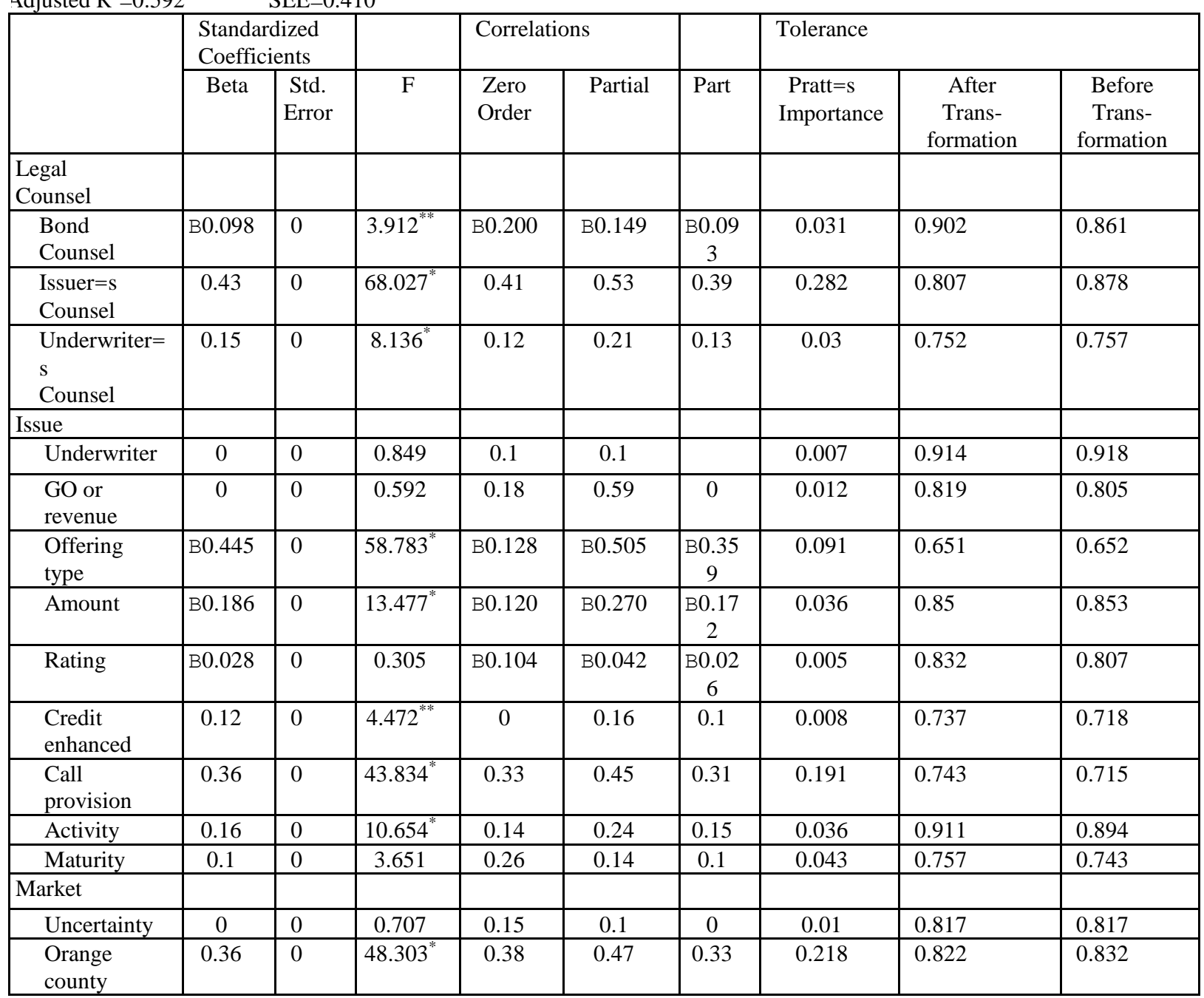

* Significant at the 0.01 level.

** Significant at the 0.05 level.

Four of the nine variables capturing issue characteristics were not significant at the 0.05 level or higher: prestige of the underwriter, classifications of general obligation or revenue bond, activity, and maturity. Five were significant in explaining differences in average interest cost: Offering type $(\beta=\mathrm{B} 0.445, \mathrm{~F}=58.783)$ and amount of the offering ( $\beta=\mathrm{B} 0.186, \mathrm{~F}=13.477)$ contributed independently to average lower costs of interest. In contrast, credit enhancement $(\beta=0.115, \mathrm{~F}=4.472)$, call $(\beta=0.360, \mathrm{~F}=43.834)$, and issuer activity $(\beta=0.160, \mathrm{~F}=10.654)$ contributed independently to average higher costs. 
Interest uncertainty was not a significant contributor to the average level of interest cost in the data examined here. However, Exhibit 5 reports that announcement of impending default by Orange County $(\beta=0.359, F=48.303)$ had a statistically significant independent positive predictive relationship with interest cost. Indeed, the announcement had the largest influence on the variability in interest cost as evidenced by Pratt=s measure of relative importance, 0.218 .

Tolerance values, the proportion of a variable $=\mathrm{s}$ variance not accounted for by other independent variables in the model, help in model diagnostics. For example, consider in Exhibit 5 the tolerance value of bond counsel. Before transforming the data for analysis, $86.1 \%$ of the variance in bond counsel was not explained by the other 13 variables (13.9\% was). After transformation, $90.2 \%$ was not explained. Hence, transforming values resulted in decreased multicollinearity and increased the explanatory power of the bond counsel variable. Variables with low tolerance values (and large negative values of Pratt $=\mathrm{s}$ measure) contribute little information to the model and suffer from increased multicollinearity. The minimum tolerance in Exhibit 5 for transformed values was 0.651 (Offering Type) and there were no negative values for Pratt $=\mathrm{s}$ measure. We believe that the level of multicollinearity in the models is acceptable based on these values.

In summary, results are generally as expected with many significant relationships between interest cost and control variables in this study. Two useful findings of this analysis are as follows: (1) Bond counsel activity independently contributed significantly to a reduction in the average net interest costs to issuers. (2) Presence of issuer $=\mathrm{s}$ counsel and activity of underwriter $=\mathrm{s}$ counsel contributed independently to a significant increase in the average interest cost to issuers in this data set.

\subsection{Summary, Implications, And Conclusion}

Statistical analysis began by collecting information regarding the reputation of legal counsel and interest cost for a sample of 340 municipal offerings during 1995. The authors used as a measure of the activity of bond counsel and underwriter $=\mathrm{s}$ counsel the rank order in a contemporaneous ranking from The Bond Buyer. An additional explanatory variable was presence of an issuer $=\mathrm{s}$ counsel. Several categorical and numeric values were included in the analysis to account for issue characteristics and market forces.

Consistent with expected results, presence of a visibly active bond counsel provided a negative independent predictive relationship with interest cost $\left(\beta_{1}=\mathrm{B} 0.098, \mathrm{~F}=3.912\right)$. For each one standard deviation change in the rank order of the transformed categories of bond counsel, average interest cost declined 0.098 standard deviation. Unexpected opposite results and interpretation applied to presence of issuer $=\mathrm{s}$ counsel $\left(\beta_{2}\right)$ with statistically significantly positive coefficients. Results were as expected for the underwriter $=$ s counsel $\left(\beta_{3}\right)$ with statistically significantly positive coefficients.

Results of this study differ from other studies of influences on interest cost in two ways. First, this study introduced legal counsel as players in the new-issues market. No other study has examined statistically this influence. Second, it applied categorical regression with optimal scaling to build the model.

The model built in this paper is consistent with the certification hypothesis, in which the signal sent to investors by issuers is conditioned on the ability of the counsel to certify the quality of the offering. After controlling for other influences, issuers in our sample received a benefit (measured by lower average interest cost) from using an active bond counsel. Here, presence of an active bond counsel may offer benefits to the issuer with respect to higher quality advice regarding features and timing of the offering, and also signal to investors the quality of the offering. Hence, in the flow of information to investors regarding the investment merit of a municipal offering, bond counsel activity is beneficial to issuers.

That was not the case for presence of issuer $=\mathrm{s}$ counsel and for activity of underwriter $=\mathrm{s}$ counsel, each of which was associated with an increase in the average cost to issuers. Market participants should not be surprised with the positive impact from underwriter $=\mathrm{s}$ counsel because it is the agent of the underwriter. However, the positive (and statistically significant) sign on categories of issuer $=\mathrm{s}$ counsel is counterintuitive and opposite what we hypothesized. 
Indeed, the notable result of this paper is the negative impact of issuer $=\mathrm{s}$ counsel. After all, we reasoned, issuer $=\mathrm{s}$ counsel is the agent of the issuer and should therefore contribute to a measurable benefit. Market participants evidently interpreted such a presence as indicating financial weakness in the issuer. In this sense, no counsel at all was better than an issuer $=\mathrm{s}$ counsel.

Agency conflict and segmentation of the market for municipal bonds explain the measured negative impact of using issuer $=\mathrm{s}$ counsel [Feroz and Wilson (1992); Kidwell, Koch, and Stock (1987)]. Because the market is segmented and localized, investors exercise monopsony power in the area in which munis are issued. Why should monopsonists rely on a signal provided by presence of an issuer $=\mathrm{s}$ counsel, whose advice may be biased in favor of the issuer? The answer is, They shouldn=t and they don=t. Investors in this segmented market are familiar with the issuer and bid for an offering at a price consistent with their perception of the bond counsel, issue characteristics, and market conditions. Investors appear to interpret use of issuer $=\mathrm{s}$ counsel as a negative signal.

The study here suggests directions for future research. First, the sample should be enlarged to include more offerings for a longer period of time in different states. Second, specification of the variables may be changed to see how sensitive are results to the specification. For example, researchers may want to develop a measure of prestige independent of the activity measure used here, then relate prestige to interest cost. Also, this study examined only the primary market. The relationship between counsel and subsequent performance in the secondary market should be examined. It is likely that issues using active counsel may enjoy a national market and experience less volatility in the secondary market. We leave these issues for future efforts.

In conclusion, issuers of municipal bonds should use the results in this paper to make them receptive to use of an active bond counsel and wary of using issuer $=\mathrm{s}$ counsel. Issue characteristics and conditions in the market may differ from those in this study, but evidence herein is sufficiently strong to place the burden of proof of benefits on the issuer $=\mathrm{s}$ counsel trying to lease its expertise and reputation to the municipality.

\section{References}

1. Akerlof, George A. AThe Market for $>$ Lemons=: Quality Uncertainty and the Market Mechanism, @ Quarterly Journal of Economics, LXXXIV (August, 1970): 488-500.

2. $\quad$ The Bond Buyer: 1994 Yearbook, New York: American Banker, 1994.

3. Bierwag, Gerald O. AComparisons of the TIC and NIC Award Bases: The Excess Costs and the Incidence of the NIC Criterion,@ The Primary Market for Municipal Debt: Bidding Rules and the Cost of Long-term Borrowing, 1981, JAI Press Inc., pp. 97B123.

4. Booth, James R., and Richard L. Smith, II. ACapital Raising, Underwriting and the Certification Hypothesis, @ Journal of Financial Economics, 15 (January/February, 1986): 261-281.

5. Braswell, Ronald C. AComparative Costs of Competitive and Negotiated Underwritings in the Municipal Bond Market: A Methodological Problem,@ Western Tax Review, 2 (January, 1981): 125-131.

6. Clarke, Wes. AThe Interest Cost Implications of the Financial Advisor Turned Underwriter,@ Public Budgeting and Finance, 17 (Fall, 1997), pp. 74-86.

7. Carter, Richard R. AUnderwriter Reputation and Repetitive Public Offerings,@ The Journal of Financial Research, XV (Winter, 1992) 341-354.

8. _ and Steven Manaster. AInitial Public Offerings and Underwriter Reputation,@ The Journal of Finance, 45 (September, 1990): 1045-1067.

9. Ettlinger, Michael, and John Koehane. AResponsibilities of Bond Counsel,: The Handbook of Municipal Bonds and Public Finance, pp. 700-723 (Robert Lamb, James Leigland, \& Stephen Rappaport, eds.). New York: Simon \& Schuster, New York Institute of Finance, 1993.

10. Feroz, Ehsan H., and Earl R. Wilson. AMarket Segmentation and the Association between Municipal Financial Disclosure and Net Interest Cost, @ The Accounting Review, 67 (July, 1992): 480-495.

11. Fortune, Peter. AThe Municipal Bond Market, Part I: Politics, Taxes, and Yields, @ New England Economic Review, Federal Reserve Bank of Boston, September/October, 1991, pp. 13-36.

12. Hayes, Samuel L., III. AInvestment Banking: Power Structure in Flux,@ Harvard Business Review, March/April, 1971, pp. 136-152. 
13. Hopewell, Michael H., and George G. Kaufman. AThe Cost of Inefficient Coupons on Municipal Bonds, @ Journal of Financial and Quantitative Analysis, IX (March, 1974): 155-164.

14. Hsueh, L. Paul, and David S. Kidwell. ABond Ratings: Are Two Better than One? @ Financial Management, 17 (Spring, 1988): 46-53.

15. Hume, Lynn S. ADisclosure, Pay-to-Play, Litigation Reform: Washington Hasn't Lost Interest in Bonds,@ The Bond Buyer, Feb. 6, 1995, p. 1.

16. Joehnk, Michael D., and David S. Kidwell. AComparative Cost of Competitive and Negotiated Underwritings in the State and Local Bond Market, @ The Journal of Finance, 34 (June, 1979): 725-731.

17. Johnson, James M., and Robert E. Miller. AInvestment Banker Prestige and the Underpricing of Initial Public Offerings, @ Financial Management, 17 (Summer, 1988): 19-29.

18. Keynes, J. M. A Treatise on Money: Volume II The Applied Theory of Money, New York: Harcourt, Brace and Company (1930).

19. Kidwell, David S., Timothy W. Koch, and Duane R. Stock. AIssue Size and Term Structure Segmentation Effects on Regional Yield Differentials in the Municipal Bond Market, @ Journal of Economics and Business, 39 (November, 1987): 339-347.

$20 . \quad$ _ a _ and Robert J. Rogowski. AState Bond Bank Issues: Method of Sale and Market Acceptance over Time,@ Financial Management, 12 (Summer, 1983): 15-20.

21. Kraft, John L. AThe Role of Bond Counsel in Public Agency Financing, @ The Municipal Bond Handbook, Vol. I, pp. 228-236 (Frank J. Fabozzi, Sylvan G. Feldstein, Irving M. Pollack, \& Frank G. Zarb, eds.). Homewood, Ill.: Dow Jones-Irwin, 1983.

22. Lamb, Robert, and Stephen P. Rappaport. Municipal Bonds, 2nd ed., New York: McGraw-Hill Book Company, New York Institute of Finance, 1987.

23. Meulman, Jacqueline J. ANonlinear Scaling Techniques for the Analysis of Large and Complicated Data Sets, @ MSRI Workshop, Berkeley, CA, March 19-29, 2001 (http://www.msri.org/publications/ln/msri/2001/ nle/meulman/1/banner/05.html).

24. Mumy, Gene E. AIssuers' Costs and Competition in the Tax-Exempt Bond Market,@ National Tax Journal, XXXI (March, 1978): 81-91.

25. Myers, S. and N. Majluf. ACorporate Financing and Investment Decisions when Firms Have Information that Investors Do Not Have, @ Journal of Financial Economics (June, 1984), pp. 187B221.

26. Osteryoung, Jerome S., Ronald C. Braswell, and Dallas R. Blevins. APIC: An Alternative Approach to Accepting Bids on Local and State Government Bonds, @ Financial Management, 8 (Summer, 1979): 36-41.

27. Peers, Alexandra. ABond Issuers Cut Outside Counsel to Trim Costs, @ The Wall Street Journal, March 14, 1988 , p. C17.

28. Petersen, John E. AInformation Flows in the Municipal Bond Market: Disclosure Needs and Processes, @ The Handbook of Municipal Bonds and Public Finance, pp. 635-699 (Robert Lamb, James Leigland, \& Stephen Rappaport, eds.). New York: Simon \& Schuster, New York Institute of Finance, 1993.

29. Ritter, Jay R. AThe 'Hot' Issue Market of 1980, @ The Journal of Business, 57 (April, 1984): 215-240.

30. Robertson, Wyndham. AThe Underwriters Have to Offer Even More, @ Fortune, 97 (January, 1973$)$ : $116-132$.

31. Roden, Peyton F., and John Bassler, AEffect of Underwriter Prestige on the Interest Cost of Municipal Bond Offerings, @ The Financial Review, 31 (3) August, 1996, pp. 641-666.

32. _ and Robert L. Bland. AIssuer Sophistication and Underpricing in the Negotiated Municipal Bond Market,@ The Journal of Financial Research, IX (Summer, 1986): 163-170.

33. Smith, Cyril V., Jr., and John B. Pirog. AThe Role of Counsel to the Underwriters, @ The Municipal Bond Handbook, Vol. I, pp. 237-251 (Frank J. Fabozzi, Sylvan G. Feldstein, Irving M. Pollack, \& Frank G. Zarb, eds.). Homewood, Ill.: Dow Jones-Irwin, 1983.

34. Smith, Richard L. AThe Choice of Issuance Procedure and the Cost of Competitive and Negotiated Underwriting: An Examination of the Impact of Rule 50, @ The Journal of Finance, 42 (July, 1987): 703-720.

35. Sorensen, Eric H. AAn Analysis of the Relationship between Underwriter Spread and the Pricing of Municipal Bonds, ¿ Journal of Financial and Quantitative Analysis, XV (June, 1980): 435-447.

36. Stevens, Amy. ALawyers and Clients: Practice of Representing Both Sides in Bond Deals Is Challenged,@ The Wall Street Journal, June 17, 1994 , p. B7.

37. Terza, Joseph V. AEstimating Linear Models with Ordinal Qualitative Regressors, @ Journal of Econometrics, 34 (1987), pp. 275B291.

38. West, Richard R. "Net Interest Cost Method of Issuing Tax-Exempt Bonds: Is It Rational?" Public Finance, 23 
(Fall, 1968): 346-354.

\section{Endnotes}

1. We rejected standard linear regression analysis for several reasons. First, estimating one coefficient for each variable would reflect arbitrary values assigned within categories. Second, standard regression requires numerical independent variables, regression with optimal scaling offers three scaling levels for each variable. Third, dealing in standard linear regression with the nonlinear relationship between a categorical variable (for example, whether or not an offering is or is not callable) and other variables is problematic when an independent variable has both high and low values associated with one value of the dependent variable. The independent variable receives only one weight, which cannot reflect the same amount of change in the predicted response for both large and small values of the independent variable. Fourth, recoding categorical variables as a series of 0B1 interval variables (for example, six bond-rating classifications into five groups) means that the model contains a separate intercept and/or slope coefficient for each combination of the levels of the categorical variables. That results in a large number of parameters to interpret.

2. The level of optimal scaling determines the optimality properties of the quantifications. Optimal quantifications are unrestricted for nominal values (for example, callable versus noncallable). The program CATREG in SPSS used in this paper orders ordinal variables (for example, activity ranking of bond counsel) in the same manner as the original categories. Finally, quantifications for numerical values are not only ordered, but also the analysis preserves the proportional difference between any two values in the corresponding original categories.

Notes 
